\title{
Erratum to: Significant interethnic differences in functional variants of PON1 and P2RY12 genes in Roma and Hungarian population samples
}

Ingrid Janicsek $\cdot$ Csilla Sipeky $\cdot$ Judit Bene $\cdot$

Balazs Duga • Bela I. Melegh · Katalin Sümegi •

Luca Jaromi · Lili Magyari $\cdot$ Bela Melegh

Published online: 4 November 2014

(C) Springer Science+Business Media Dordrecht 2014

Erratum to: Mol Biol Rep

DOI 10.1007/s11033-014-3762-9

Fifth author name should be read as Bela I. Melegh instead of Bela Melegh.

The online version of the original article can be found under doi:10.1007/s11033-014-3762-9.

I. Janicsek · C. Sipeky $\cdot$ J. Bene $\cdot$ B. Duga .

B. I. Melegh (凹) · K. Sümegi · L. Jaromi · L. Magyari ·

B. Melegh

Department of Medical Genetics, Szentágothai János Research

Center, Clinical Center, University of Pécs, Szigeti 12,

Pécs 7624, Hungary

e-mail: bela.melegh@pte.hu; melegh.bela@pte.hu

I. Janicsek

e-mail: janicsek.ingrid@gmail.com 